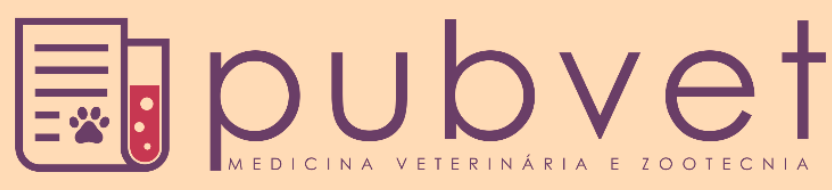

https://doi.org/10.31533/pubvet.v13n10a426.1-7

\title{
Desempenho produtivo na recria de fêmeas nelore recebendo diferentes suplementações
}

\author{
João Victor de Souza Martins ${ }^{1 *} \bullet$, Renato Augusto Peralta Freire ${ }^{1}$, Rafael de Oliveira Lima ${ }^{1} \bullet$, \\ Lucas Gomes da Silva ${ }^{2} \bullet$, Danaila Bruneli Fernandes Gama ${ }^{2} \bullet$, Jéssica Thaís Gabe ${ }^{\circ}$, Ester \\ Lays Martins Ribeiro ${ }^{1} \bullet$, Wellington Pereira Soares ${ }^{2}{ }^{\bullet}$, Rafela Thais Benedito Alves ${ }^{4}$, Rodrigo \\ Gonçalves Mateus ${ }^{\circ}{ }^{\circ}$
}

${ }^{1}$ Acadêmico (a) de Zootecnia da Universidade Católica Dom Bosco. Campo Grande-MS, Brasil

${ }^{2}$ Acadêmico (a) de Medicina Veterinária da Universidade Católica Dom Bosco. Campo Grande - MS, Brasil

${ }^{3}$ Acadêmico (a) de Agronomia da Universidade Católica Dom Bosco. Campo Grande - MS, Brasil

${ }^{4}$ Pós-Graduanda em Ciências Ambientais e Sustentabilidade Agropecuária pela Universidade Católica Dom Bosco. Campo Grande, Brasil

${ }^{5}$ Professor da Universidade Católica Dom Bosco, Departamento de Zootecnia e Medicina Veterinária. Campo Grande - MS, Brasil

*Autor de correspondência,E-mail: joaomartins.zootec@gmail.com

Resumo. Objetivou-se com o presente estudo avaliar o desempenho produtivo de fêmeas Nelore na recria, recebendo suplementação mineral proteico, e proteico energético em pastagem de Urucloa brizantha cv Marandu no período de transição águas - seca e sua implicação sobre o ganho de peso dos animais. O estudo foi realizado na fazenda Relíquia, localizada no município de Ribas do Rio Pardo - MS, Brasil, utilizando 81 dias experimentais. Foram utilizadas 60 novilhas da raça nelore, divididas em dois lotes de 30 animais, cada lote por piquete, em pastejo contínuo, com peso médio corporal (PC) de 304 $\pm 82 \mathrm{~kg}$ e idade de 18 meses para avaliação do ganho de peso. Os animais receberam 2 estratégias nutricionais: suplemento mineral proteico (SMP) na proporção de 72 $\mathrm{g} /$ animal/dia (0,02\% do PV), e suplemento proteico energético (SPE) 271,6 g/animal/dia $(0,08 \%$ do PV). Amostras de pasto foram coletadas a cada 20 dias nas áreas experimentais para determinação da disponibilidade de MS/ha de pasto, e para avaliação da composição químico-bromatológica. $\mathrm{O}$ desempenho produtivo dos animais apresentou diferença $(\mathrm{P}>$ $0,05)$ no peso corporal final, ganho de peso total e ganho médio diário, para os 81 dias de experimento, sendo que o desempenho do Mineral Proteico foi superior ao Proteico Energético. A massa de forragem observada no pasto de capim Marandu durante o experimento foi de $2077,5 \mathrm{~kg}, 1305,0 \mathrm{~kg}, 800,0 \mathrm{~kg}$ e 597,5 kg de MS/há nos meses março, abril, maio e junho, respectivamente. $\mathrm{O}$ grupo de animais do tratamento com suplemento mineral proteico, apresentaram peso corporal final de $328,27 \mathrm{~kg}$, ganho de peso total de $24,96 \mathrm{~kg}$, ganho médio diário de $0,308 \mathrm{~kg} / \mathrm{animal} / \mathrm{dia}$ e o do suplemento proteico energético de $325,27 \mathrm{~kg}, 19,48 \mathrm{~kg}$, e $0,240 \mathrm{~kg} /$ dia, respectivamente. A suplementação mineral proteica foi superior ao tratamento com proteico energético em relação ao peso corporal final dos animais avaliados.

Palavras-chave: Ganho de peso, proteico energético, mineral proteico

\section{Productive performance in the recreate of nellore females receiving different supplements}

Abstract. The objective of this study was to evaluate the productive performance of Nellore females in the rebuilds, receiving protein mineral supplementation, and energetic protein in the pasture of Urucloa Brizantha cv Marandu in the transition period-drought and its implication on the Weight gain of the animals. The study was carried out at the relic 
Farm, located in the municipality of Ribas do Rio Pardo - MS, Brazil, using 81 experimental days. We used 60 Nellore heifers, Nuliparas, divided into two batches of 30 animals, each lot per picket, in continuous grazing, with average body weight (BW) of 304 $\pm 82 \mathrm{~kg}$ and age of 18 months for weight gain evaluation. The animals received 2 nutritional strategies: Protein mineral Supplement (SMP) in the proportion of $72 \mathrm{~g} / \mathrm{animal} / \mathrm{day}(0.02 \%$ of PV), and Energy protein Supplement (SPE) $271.6 \mathrm{~g} / \mathrm{animal} /$ day (0.08\% of PV). Pasture samples were collected every 20 days in the experimental areas to determine the DM/ha availability of pasture, and to evaluate the chemical-bromatologic composition. The productive performance of the animals showed difference $(\mathrm{P}>0.05)$ in the final body weight, total weight gain and average daily gain, for the 81 days of the experiment, and the performance of the protein mineral was higher than the energetic protein. The forage mass observed in Marandu grass pasture during the experiment was $2077.5 \mathrm{~kg}, 1305.0 \mathrm{~kg}, 800.0$ $\mathrm{kg}$ and $597.5 \mathrm{~kg}$ of DM/ago in the months March, April, May and June, respectively. The group of animals of the treatment with protein mineral supplement presented final body weight of $328.27 \mathrm{~kg}$, total weight gain of $24,96 \mathrm{~kg}$, Average daily gain of 0.308 $\mathrm{kg} / \mathrm{animal} / \mathrm{day}$ and the energetic protein supplement of $325.27 \mathrm{~kg}, 19.48 \mathrm{~kg}$, and 0.240 $\mathrm{kg} / \mathrm{day}$, respectively. Protein mineral supplementation was superior to the treatment with energetic protein in relation to the final body weight of the animals evaluated.

Keywords: weight gain, energetic protein, protein mineral

\section{Rendimiento productivo de la recría de las hembras Nellore con diferentes tipos de suplementación}

Resumen. El objetivo de este estudio fue evaluar el rendimiento productivo de las hembras Nellore en la cría, recibiendo suplementación mineral-proteica, y proteico-energética en pasturas de Urucloa brizantha cv Marandu durante el período de transición de agua seca y su implicación en el aumento de peso de los animales. El estudio se llevó a cabo en la granja Reliquia, ubicada en Ribas do Rio Pardo (Brasil), utilizando 81 días experimentales. Se utilizaron sesenta novillas Nellore, divididas en dos lotes de 30 animales, cada lote por potrero, en pastoreo continuo, con un peso corporal promedio (PC) de $304 \pm 82 \mathrm{~kg}$ y 18 meses de edad para evaluar el aumento de peso. Los animales recibieron 2 estrategias nutricionales: suplemento mineral de proteínas (SMP) a razón de $72 \mathrm{~g} / \mathrm{animal} / \mathrm{día}(0.02 \%$ de PV), y suplemento energético de proteínas (SPE) $271.6 \mathrm{~g} /$ animal/día (0.08\%). \% de PV). Se recolectaron muestras de pasto cada 20 días en las áreas experimentales para determinar la disponibilidad de MS/ha de pasto y para evaluar la composición química (bromatológica). El rendimiento productivo de los animales mostró una diferencia (P> 0.05 ) en el peso corporal final, el aumento de peso total y el aumento diario promedio, durante los 81 días de experimento, siendo la suplementación mineral-proteica superior al proteico-energético. La masa forrajera observada en el pasto de Marandu durante el experimento fue de $2077.5 \mathrm{~kg}, 1305.0 \mathrm{~kg}, 800.0 \mathrm{~kg}$ y $597.5 \mathrm{~kg}$ de MS/ha en marzo, abril, mayo y junio, respectivamente. El grupo de animales tratados con suplementación mineralproteica presentó un peso corporal final de $328.27 \mathrm{~kg}$, un aumento de peso total de 24.96 $\mathrm{kg}$, un aumento diario promedio de $0.308 \mathrm{~kg} / \mathrm{animal} / \mathrm{d}$ áa y la suplementación proteicoenergética de $325.27 \mathrm{~kg}, 19.48 \mathrm{~kg}$ y $0.240 \mathrm{~kg} /$ día, respectivamente. La suplementación mineral-proteica fue superior a la suplementación proteico-energética con relación al peso corporal final de los animales evaluados.

Palabra clave: ganancia de peso, proteína energética, proteína mineral

\section{Introdução}

O Brasil se destaca na pecuária global por possuir o segundo maior rebanho de bovinos e o segundo maior produtor de carne do mundo, contando com aproximadamente 218,2 milhões de bovinos, criados em 171,8 milhões de hectares de pastagens (ANUALPEC, 2019). A maior parte do rebanho brasileiro se alimenta basicamente de gramíneas forrageiras, as quais constituem a base de sustentação da pecuária 
nacional (Ferraz \& Felício, 2010; Moraes et al., 2010; Moraes et al., 2006; Pereira et al., 2010). No entanto, a produtividade e qualidade dessas gramíneas sofrem variação sazonal às condições climáticas, não permitindo desempenho constante dos animais (Moreira et al., 2004a; Moreira et al., 2004b). Segundo Casagrande et al. (2010) a pastagem é a principal fonte de alimento para os animais de baixo custo, porém a maior parte das pastagens encontra-se em algum estágio de degradação. Na situação em que apenas a forragem não é capaz de suprir as exigências de produção do animal, faz-se necessária a utilização de recursos nutricionais suplementares, os quais se apresentem mais convenientes e adaptados, complementando as demandas para produção animal (Fernandes et al., 2016).

Aproximadamente $80-85 \%$ dos animais no Brasil apresentam genes de origem zebuína, seja como animais puros, seja por cruzamentos, sendo o Nelore a raça predominante (Ferraz \& Felício, 2010). Mesmo com a predominância de animais mais rústicos e adaptados às condições de criação típicas de ambiente tropical, a eficiência produtiva dos sistemas de produção de gado de corte no Brasil é altamente dependente de medidas racionais de manejo alimentar desses animais. Esse cenário pode justificar a adoção de períodos parciais de suplementação, e ser de grande relevância para o aumento da eficiência econômica de sistemas de produção a pasto (Malafaia et al., 2007; Prado, 2010).

O objetivo do presente estudo foi avaliar o desempenho produtivo de fêmeas Nelore na recria, recebendo suplementação mineral proteico, e proteico energético em pastagem de Urucloa brizantha cv Marandu no período de transição águas - seca.

\section{Material e métodos}

O experimento foi realizado na fazenda Relíquia, localizada no município de Ribas do Rio Pardo MS, Brasil, o qual compreendeu parte da fase de recria dos animais no período de transição águas e secas (26/03/2018 a 15/06/2018), totalizando 81 dias de período experimental.

Foram utilizadas 60 novilhas da raça Nelore, nulíparas, divididas em dois lotes de 30 animais, cada lote por piquete, em pastejo contínuo, com peso médio corporal (PC) de $304 \pm 82 \mathrm{~kg}$ e idade de 18 meses para avaliação do ganho de peso. No início do experimento, os animais foram identificados individualmente com brinco na orelha e everminados com ivermectina 1\% (Ivomec, Merial, Paulínea, São Paulo, Brazil).

Houve adaptação dos animais ao pasto, manejo e suplemento tendo duração de sete dias. A área experimental, formada com Urucloa brizantha cv Marandu, foi dividida em dois piquetes (16 ha cada). Os animais foram rotacionados nos piquetes a cada 15 dias, a fim de não haver favorecimento pela área experimental. Os suplementos foram fornecidos diariamente, em cocho coletivo, não coberto, com acesso duplo disponibilizando uma metragem linear de $60 \mathrm{~cm}$ por novilha e localizado a 15 metros da fonte de água. Todos os animais tiveram acesso à água ad libitum.

Os animais receberam duas estratégias nutricionais: suplemento mineral proteico (SMP) na proporção de $0,4 \%$ do $\mathrm{PV}$, e suplemento proteico energético (SPE) na proporção de $0,8 \%$ do $\mathrm{PV}$, seguindo a orientação recomendada pelo fabricante do produto. As novilhas foram suplementadas diariamente às $10 \mathrm{~h}$, após o pico de pastejo matinal. Antes do fornecimento do suplemento, as sobras foram recolhidas e pesadas, para ajuste do fornecimento de suplemento. A composição dos suplementos pode ser observada na Tabela 1.

As amostras de pasto foram coletadas a cada 20 dias nas áreas experimentais. Para determinação da quantidade disponível de pasto, foram coletadas amostras em 10 pontos de cada piquete, aleatoriamente, cortadas a cinco $\mathrm{cm}$ de altura do solo. Para avaliação da qualidade nutricional do pasto, foram colhidas amostras pelo método de pastejo simulado (Mott \& Lucas, 1952) e levadas ao Laboratório de Biotecnologia aplicada à Nutrição Animal da Universidade Católica Dom Bosco, para realização dos ensaios de composição bromatológica.

$\mathrm{Na}$ avaliação bromatológica foram determinados os teores de matéria seca (MS) (método 930,15; AOAC, 2000), matéria mineral (MM) (método 942,05; AOAC 2005) e proteína bruta (PB) $(\mathrm{N} \times 6,25$; método 984,13; AOAC (2005). A determinação de fibra em detergente neutro (FDN) foi realizada de acordo com Mertens (2002). Os teores de fibra em detergente ácido (FDA) pela solubilização da celulose 
em ácido sulfúrico (H2SO4) utilizando o método de Robertson \& Van Soest (1981). A composição bromatológica do pasto pode ser observada na Tabela 2.

Tabela 1. Composição nutricional dos suplementos

\begin{tabular}{lcc}
\hline & \multicolumn{2}{c}{ Suplementos } \\
\cline { 2 - 3 } Item & Mineral Proteico & Proteico Energético \\
\cline { 2 - 3 } Cobalto & 100,00 & 11,25 \\
Cobre & 850,00 & 337,50 \\
Flúor & 650,00 & 140,00 \\
Iodo & 57,00 & 23,33 \\
Manganês & 750,00 & 113,00 \\
NDT estimado & - & 480,00 \\
Salinemicina & - & 180,00 \\
Selênio & 10,00 & 6,08 \\
Zinco & 2000,00 & 1134,00 \\
\hline & & $\mathrm{g} / \mathrm{kg}$ \\
Cálcio (mín.) & 98,00 & 50,00 \\
Cálcio (máx.) & 102,00 & 80,00 \\
Sódio & 100,00 & 64,00 \\
Fósforo & 65,00 & 14,00 \\
Matéria mineral & - & 368,00 \\
NNP EQ. Proteina & - & 151,70 \\
Enxofre & 13,00 & 4,60 \\
Proteína Bruta & 580,00 & 200,00 \\
Umidade & - & 120,00 \\
\hline Garantia nuticion & &
\end{tabular}

Garantia nutricional informada pelo fabricante

A avaliação do desempenho pelo ganho de peso médio diário (GMD) (kg), foi determinada pela diferença entre o PC final e PC inicial (restrição de sólidos e líquidos por 16 horas-jejum) dividido pelo total de dias do período experimental. No entanto, pesagens intermediárias, a cada 20 dias, foram realizadas para ajustar a oferta de suplemento.

Tabela 2. Composição bromatológica da Urucloa brizantha cv. Marandu

\begin{tabular}{lccccc}
\hline \multirow{2}{*}{ Componentes } & \multicolumn{4}{c}{ Períodos } & \multirow{2}{*}{ Média } \\
\cline { 2 - 5 } & Março & Abril & Maio & Junho & \\
\hline Matéria Seca (\%) & 36,05 & 55,14 & 50,58 & 54,18 & 48,98 \\
Proteína Bruta (\% da MS) & 3,83 & 4,12 & 3,87 & 3,29 & 3,77 \\
Extrato etéreo (\% da MS) & 0,91 & 1,07 & 0,92 & 0,9 & 0,95 \\
FDN corrig. (\% da MS) & 64,93 & 63,71 & 69,4 & 75,63 & 68,42 \\
FDA corrig. (\% da MS) & 33,94 & 32,91 & 34,81 & 38,67 & 35,08 \\
Matéria mineral (\% da MS) & 3,97 & 4,87 & 5,26 & 4,81 & 42,73 \\
\hline
\end{tabular}

FDN - Fibra em detergente neutro; FDA - Fibra em detergente ácido; MS - Matéria seca; pastejo simulado.

$\mathrm{O}$ delineamento experimental foi inteiramente ao acaso, sendo os dados submetidos à análise de variância utilizando o procedimento MIXED do SAS (2004) versão 9.1.2 (Statistical Analysis System Institute, Inc., Cary, North Carolina, USA).

\section{Resultados e discussão}

O desempenho produtivo dos animais que receberam o suplemento mineral proteico (SMP) e proteico energético (SPE) apresentou diferença $(\mathrm{P}>0,05)$ no peso corporal final, ganho de peso total e ganho médio diário, para os 81 dias de experimento, sendo que o mineral proteico apresentou resultado superior, como indica a Tabela 3. 
O grupo de animais do tratamento com suplemento mineral proteico apresentou peso corporal final de $328,27 \mathrm{~kg}$, ganho de peso total de $24,96 \mathrm{~kg}$, ganho médio diário de $0,308 \mathrm{~kg} /$ animal/dia e o do suplemento proteico energético de $325,27 \mathrm{~kg}, 19,48 \mathrm{~kg}$, e 0,240 kg/dia, respectivamente. Provavelmente o tratamento com SPE não eliminou a deficiência proteica, o que impossibilitou que a reciclagem de nitrogênio no rúmen compensasse o baixo teor de $\mathrm{PB}$ da pastagem, não atendendo os requisitos mínimos de proteína bruta preconizados compêndios de exigências (7\%) (Goes et al., 2009).

Tabela 3. Resultado do desempenho de novilhas de corte recebendo suplemento mineral proteico e proteico energético.

\begin{tabular}{lccc}
\hline \multirow{2}{*}{ Desempenho } & \multicolumn{2}{c}{ Suplementos } \\
\cline { 2 - 3 } & Mineral proteico & Proteico energético & P \\
\hline Peso corporal inicial (kg) & 303,31 & 305,79 & 0,6560 \\
Peso corporal final (kg) & 328,27 & 325,27 & 0,028 \\
Ganho de peso total (kg) & 24,96 & 19,48 & 0,028 \\
Ganho médio diário (kg/dia) & 0,308 & 0,240 & 0,028 \\
\hline
\end{tabular}

O teor médio de proteína bruta $(\mathrm{PB})$ na forragem obtida via pastejo simulado manual teve média de $3,77 \%$ (Tabela 2) e abaixo de 7,0\% de PB na dieta basal, considerado como nível crítico para satisfazer as exigências microbianas em compostos nitrogenados e permitir a fermentação dos carboidratos fibrosos no rúmen (Lazzarini et al., 2009; NRC, 2001).

O desempenho superior para as novilhas recebendo MP pode ser atribuído ao maior consumo de compostos nitrogenados, propiciando assim melhor uso da forragem consumida pelos animais, uma vez que os suplementos MP possuíam 58\% de PB, enquanto o SPE continha 20\% de PB. Moraes et al. (2006) avaliando níveis de proteína ( 8,16 e $24 \%$ de PB) em suplementos no período de transição seca e águas, verificaram aumento linear no desempenho produtivo dos animais com o aumento no teor de proteína bruta dos suplementos.

$\mathrm{Na}$ Tabela 4, estão apresentados os dados referentes ao desempenho produtivo das novilhas, disponibilidade de pasto e oferta de forragem, não havendo diferença $(\mathrm{P}>0,05)$, para o peso corporal, ganho de peso e ganho médio diário dos meses de abril, maio e junho.

Tabela 4. Média do desempenho de novilhas de corte recebendo suplementos Mineral proteico e Proteico energético de abril à junho.

\begin{tabular}{lccc}
\hline \multirow{2}{*}{ Desempenho } & \multicolumn{3}{c}{ Suplementos } \\
\cline { 2 - 3 } & Mineral proteico & Proteico energético & P \\
\hline Peso corporal inicial $(\mathrm{kg})$ & 303,31 & 305,79 & 0,656 \\
Peso corporal abril $(\mathrm{kg})$ & 337,97 & 339,23 & 0,910 \\
Ganho de peso abril $(\mathrm{kg})$ & 34,63 & 33,83 & 0,072 \\
Ganho médio diário abril (kg/dia) & 1,15 & 1,13 & 0,069 \\
\hline Peso corporal maio (kg) & 338,90 & 0,910 \\
Ganho de peso maio(kg) & 0,93 & 0,072 \\
Ganho médio diário maio (kg/dia) & 0,03 & $-0,53$ & 0,069 \\
\hline Peso corporal junho $(\mathrm{kg})$ & 327,07 & $-0,02$ & 0,910 \\
Ganho de peso junho(kg) & $-11,83$ & 324,03 & 0,072 \\
Ganho médio diário junho (kg/dia) & $-0,56$ & $-14,67$ & 0,069 \\
\hline
\end{tabular}

A massa de forragem observada no pasto de capim-Marandu durante o experimento foi de 2077,5 $\mathrm{kg}, 1305,0 \mathrm{~kg}, 800,0 \mathrm{~kg}$ e $597,5 \mathrm{~kg}$ de $\mathrm{MS} / \mathrm{ha}$ nos meses março, abril, maio e junho respectivamente (Tabela 5). Valor este, abaixo do valor mínimo de $4.500 \mathrm{~kg}$ de MS total ha-1 preconizados por Silva et al. (2009) para garantir seletividade e ganhos individuais satisfatórios sem comprometer o ganho por área. Entretanto, a média de disponibilidade de MS de 2077,5 $\mathrm{kg} \mathrm{ha}^{-1}$ de MS está acima do estipulado por Minson (2012) de 2000 ( $\mathrm{kg} \mathrm{ha}^{-1}$ de MS), como sendo o mínimo para que a disponibilidade de MST não ocasione diminuição no consumo do pasto, além de não oferecer limitação à capacidade seletiva dos animais. 
Tabela 5. Média da disponibilidade de pasto no período inicial à junho.

\begin{tabular}{lcccc}
\hline Mês & Março & Abril & Maio & Junho \\
\hline Disponibilidade de Matéria seca (kg/ha) & 2077,5 & 1305,0 & 800,0 & 597,5 \\
Taxa de lotação (UA/ha) & 1,27 & 1,41 & 1,41 & 1,36 \\
Oferta de forragem (kg/100 kg PC) & 20,78 & 13,05 & 8,0 & 5,98 \\
\hline
\end{tabular}

Houve ganho de peso dos animais no período inicial (abril), não diferindo entre os tratamentos ( $\mathrm{P}$ > $0,05)$. A relação de ganho de peso pode ser explicada devido a massa de forragem existente ser suficiente para promover o ganho de peso nos animais, e o efeito do ganho compensatório.

Antes de iniciar o experimento, os animais não recebiam suplementação e eram mantidos em pastagens com pouca disponibilidade e de baixa qualidade. Assim, quando os animais passam por um período de restrição e o crescimento é reduzido, o animal se recupera em taxas mais aceleradas, causando esse efeito denominado de ganho compensatório (Euclides et al., 1998; Fontes et al., 2007; Prado, 2010). Contudo, a disponibilidade de matéria seca nos meses de maio e junho deste estudo, apresentaram média de 800 e 597,5 kg/ha, respectivamente, podendo ser relacionada à baixa eficiência dos tratamentos (Tabela 5), não diferindo entre si.

Por outro lado, a suplementação em níveis mais altos pode se tornar uma alternativa de manejo para o período de transição águas e secas, quando se desejar produzir uma elevada taxa de lotação ou aumentar a produção por área. Isso se torna possível pelo efeito substitutivo entre suplemento e forragem, proporcionando acúmulo de forragem disponível para os animais (Goes et al., 2009). Porto et al. (2011) também observaram que altas ofertas de suplementos reduzem o consumo de pasto, contudo aumentam o desempenho produtivo, devido à maior ingestão de energia durante o período seco, podendo resultar em maiores taxas de lotação.

\section{Conclusão}

A suplementação de novilhas com o mineral proteico e proteico energético no período seco pode ser utilizada desde que a disponibilidade de pastagem seja superior a $1305,0 \mathrm{~kg}$. Sendo importante garantir no mínimo de $13,05 \mathrm{~kg}$ de oferta de forragem para $100 \mathrm{~kg}$ de peso corporal. Contudo, a suplementação mineral proteica foi superior ao tratamento com proteico energético em relação ao desempenho produtivo dos animais avaliados neste experimento.

\section{Referências bibliográficas}

ANUALPEC. (2019). Anuário da Pecuária Brasileira (20th ed. Vol. 1). São Paulo, São Paulo, Brasil: Instituto FNP.

AOAC. (2005). - Association Official Analytical Chemist (2005) (Official Methods of Analysis (18th ed.) ed.). Gaitherburg, Maryland, USA: AOAC.

Casagrande, D. R., Ruggieri, A. C., Janusckiewicz, E. R., Gomide, J. A., Reis, R. A. \& Valente, A. L. d. S. (2010). Características morfogênicas e estruturais do capim-marandu manejado sob pastejo intermitente com diferentes ofertas de forragem. Revista Brasileira de Zootecnia, 39(10):2108-2115.

Euclides, V. P. B., Euclides Filho, K., De Arruda, Z. J. \& Figueiredo, G. R. (1998). Desempenho de novilhos em pastagens de Brachiaria decumbens submetidos a diferentes regimes alimentares. Revista Brasileira de Zootecnia, 27(2):246-254.

Fernandes, R. M., Almeida, C. M., Carvalho, B. C., Alves Neto, J. A., Mota, V. A. C., Resende, F. D. \& Siqueira, G. R. (2016). Effect of supplementation of beef cattle with different protein levels and degradation rates during transition from the dry to rainy season. Tropical Animal Health and Production, 48(1):95-101.

Ferraz, J. B. S. \& Felício, P. E. (2010). Production systems - An example from Brazil. Meat Science, 84(2):238-243.

Fontes, C. A. F., Guimarães, R. F. M., Izabel, M., Vieira de Almeida, O. F. d. C., Almeida, F. Q. \& Faria Sant'Ana, N. (2007). Avaliação do ganho compensatório em novilhos mestiços Holandês-Gir: consumo e desempenho. Revista Brasileira de Zootecnia, 36(3):698-708. 
Goes, R. H. T. B., Mancio, A. B., Alves, D. D., Lana, R. P., Cecon, P. R., Freitas, T. B. \& Brabes, K. C. S. (2009). Desempenho de novilhos mantidos em pastagens submetidos à suplementação protéica e protéico-energética, durante a época seca. Revista Brasileira de Saúde e Produção Animal, 10(4).

Lazzarini, I., Detmann, E., Sampaio, C. B., Paulino, M. F., Valadares Filho, S. d. C., Souza, M. A. \& Oliveira, F. A. (2009). Intake and digestibility in cattle fed low-quality tropical forage and supplemented with nitrogenous compounds. Revista Brasileira de Zootecnia, 38(10):2021-2030.

Malafaia, P., Gonçalves, J. C. S., Ferreira, A. E. \& Morenz, M. J. F. (2007). Desempenho de bovinos mestiços leiteiros submetidos à suplementação protéico-energética em diferentes meses da estação da seca. Revista Brasileira de Medicina Veterinária, 29(2):69-72.

Mertens, D. R. (2002). Gravimetric determination of amylase-treated neutral detergent fiber in feeds with refluxing in beakers or crucibles: collaborative study. Journal of AOAC International, 85(6):1217-1240.

Minson, D. (2012). Forage in ruminant nutrition (Vol. 1). New York: Academic Press.

Moraes, E. H. B. K., Paulino, M. F., Valadares Filho, S. C., Moraes, K. A. K., Detmann, E. \& Gonçalves, M. (2010). Avaliação nutricional de estratégias de suplementação para bovinos de corte durante a estação da seca. Revista Brasileira de Zootecnia, 39(3):608-616.

Moraes, E. H. B. K., Paulino, M. F., Zervoudakis, J. T., Valadares Filho, S. d. C., Cabral, L. d. S., Detmann, E., . . . Moraes, K. A. K. (2006). Associação de diferentes fontes energéticas e protéicas em suplementos múltiplos na recria de novilhos mestiços sob pastejo no período da seca. Revista Brasileira de Zootecnia, 38(10):2021-2030.

Moreira, F. B., Prado, I. N., Cecato, U., Wada, F. Y. \& Mizubuti, I. Y. (2004a). Forage evaluation, chemical composition, and in vitro digestibility of continuously grazed star grass. Animal Feed Science and Technology, 113(1):239-249. doi: https://doi.org/10.1016/j.anifeedsci.2003.08.009.

Moreira, F. B., Prado, I. N., Cecato, U., Zeoula, L. M., Wada, F. Y. \& Torii, M. S. (2004b). Níveis de suplementação com sal mineral proteinado para novilhos Nelore terminados em pastagem no período de baixa produção forrageira. Revista Brasileira de Zootecnia, 33(6):1814-1821.

Mott, G. O. \& Lucas, H. L. (1952). The design, conduct and interpretation of grazing trials on cultivated and improved pastures. Paper presented at the International Grassland Congress, Pennsylvania, USA.

NRC. (2001). Nutrient Requirements of Dairy Cattle (7th rev. ed.). Washington: Natl. Acad. Press, Washington, DC.

Pereira, E. S., Pimentel, P. G., Queiroz, A. C. \& Mizubuti, I. Y. (2010). Novilhas leiteiras (Vol. 1). Fortaleza, Ceará: Graphiti Gráfica e Editora Ltda.

Porto, M. O., Paulino, M. F., Detmann, E., Valadares Filho, S. C., Sales, M. F. L., Cavali, J., . . Acedo, T. S. (2011). Ofertas de suplementos múltiplos para tourinhos Nelore na fase de recria em pastagens durante o período da seca: desempenho produtivo e características nutricionais. Revista Brasileira de Zootecnia, 40(11):2548-2557.

Prado, I. N. (2010). Produção de bovinos de corte e qualidade da carne (Vol. 1). Maringá, Paraná, Brasil: Eduem.

Robertson, J. B. \& Van Soest, P. J. (1981). The detergent system of analysis and its application to human foods. The analysis of dietary fiber in food, 3123.

SAS. (2004). SAS/STAT User guide, Version 9.1.2. Cary, NC, USA: SAS Institute Inc.

Silva, F. F., Sá, J. F., Schio, A. R., Ítavo, L. C. V., Silva, R. R. \& Mateus, R. G. (2009). Suplementação a pasto: disponibilidade e qualidade x níveis de suplementação x desempenho. Revista Brasileira de Zootecnia, 38(1):371-389.

Recebido: 16 de setembro, 2019.

Aprovado: 25 de outubro, 2019.

Publicado: 5 de dezembro, 2019.

Licenciamento: Este artigo é publicado na modalidade Acesso Aberto sob a licença Creative Commons Atribuição 4.0 (CC-BY 4.0), a qual permite uso irrestrito, distribuição, reprodução em qualquer meio, desde que o autor e a fonte sejam devidamente creditados. 